\title{
Properties of balance: A pendulum effect in corporate entrepreneurship
}

\author{
Michael H. Morris ${ }^{a, *}$, Jurie van Vuuren ${ }^{b}$, Jeffrey R. Cornwall ${ }^{c}$, \\ Retha Scheepers ${ }^{d}$
}

\author{
a Spears School of Business, Oklahoma State University, Stillwater, OK 74078, U.S.A. \\ ${ }^{\mathrm{b}}$ Department of Business Management, University of Pretoria, Pretoria, South Africa \\ 'College of Business Administration, Belmont University, Nashville, TN 37212, U.S.A. \\ ${ }^{\mathrm{d}}$ Department of Business Management, Stellenbosch University, Stellenbosch, South Africa
}

\section{KEYWORDS \\ Balance; \\ Chaos; \\ Corporate \\ entrepreneurship; \\ Paradox; \\ Work climate}

\begin{abstract}
Organizations tend to evolve in ways that are inherently resistant to entrepreneurship. Yet, entrepreneurship is instrumental for ensuring the long-term sustainability of any enterprise. The key to maintaining relatively high levels of entrepreneurship within a company lies in understanding the basic nature of the entrepreneurial experience, recognizing the inherent entrepreneurial potential of all employees, and creating work climates that allow employees to act on that potential. Five primary design elements are identified for facilitating such climates. Underlying these design elements is a set of seemingly conflicting properties. The challenge to companies is to achieve a balance between these properties whereby they are allowed to co-exist. Approaches to implementing this balance are addressed herein. (C) 2009 Kelley School of Business, Indiana University. All rights reserved.
\end{abstract}

\section{Basic assumptions of entrepreneurial behavior}

Corporate entrepreneurship (CE) can take many forms (see Morris, Kuratko, \& Covin, 2008), but it is ultimately concerned with fostering innovative, risk-taking, and proactive behaviors in established organizations. These behaviors result in

\footnotetext{
* Corresponding author.

E-mail addresses: mhm@okstate.edu (M.H. Morris), Jurie.VanVuuren@up.ac.za (J. van Vuuren), cornwallj@mail.belmont.edu (J.R. Cornwall), mjs@sun.ac.za (R. Scheepers).
}

competitive advantage by enabling firms to become more flexible and adaptable, and aggressive, faster, and better at generating novel products, services, and process improvements. As external conditions become more dynamic, hostile, and complex, $\mathrm{CE}$ becomes an especially critical factor for both the financial and non-financial performance of the firm.

The challenge of getting firms to become more entrepreneurial is, in some ways, similar to the challenge of getting them to adopt any orientation, such as becoming more customer-driven, efficient, or ethical. At the root of such change is a basic assumption about human nature and human capabilities. Do company executives assume that 
entrepreneurship is a capability that a chosen few are endowed with, making the challenge one of simply recruiting and investing in such individuals? Or, do they assume that all employees have innate entrepreneurial potential, posing the greater challenge of creating a work climate that will enable staff members to discover and act upon that potential?

Depending on which of these assumptions is adopted, we can identify two general philosophies regarding how to foster higher levels of entrepreneurship within a firm. The first of these might be termed "pick the winners," while the second can be labeled "step up to the plate." With the "pick the winners" approach, the firm attempts to identify people who are 'entrepreneurial' and then charges them with becoming champions of innovative projects. When there is not much entrepreneurial activity occurring within the firm, it is easy to assume that current employees are simply not very entrepreneurial, and so management must look externally to find the right kinds of people. The problem with this approach is that predicting who will be entrepreneurial is much like predicting who will be a great leader in a given situation. No valid and reliable method exists for making such predictions. Even those who have done something entrepreneurial in the past are not necessarily going to repeat that behavior in a new context.

The "step up to the plate" approach recognizes that literally every employee has entrepreneurial potential. The key to tapping that potential lies in creating the kind of work environment where employees are willing to develop creative concepts, demonstrate tenacity in promoting those concepts, and risk failure as they persevere in implementing those concepts. At the core of this approach is the recognition that while entrepreneurial behavior on the part of individuals is neither controllable nor predictable, it can be fostered and facilitated.

In what sort of work climates are employees most likely to step up to the plate? A number of elements must be considered in designing the appropriate workplace environment, including aspects of strategy, structure, culture, controls, and human resource management practices. The key to each of these areas, however, is the concept of balance, or the achievement of a point of relative equality and co-existence between two opposing forces. It is these opposing forces that give rise to sustainable entrepreneurship in companies. In the sections that follow, we will examine how the principle of balance can be applied to key aspects of the work environment in ways that foster entrepreneurial behavior.

Figure 1. Six types of corporate entrepreneurship outcomes

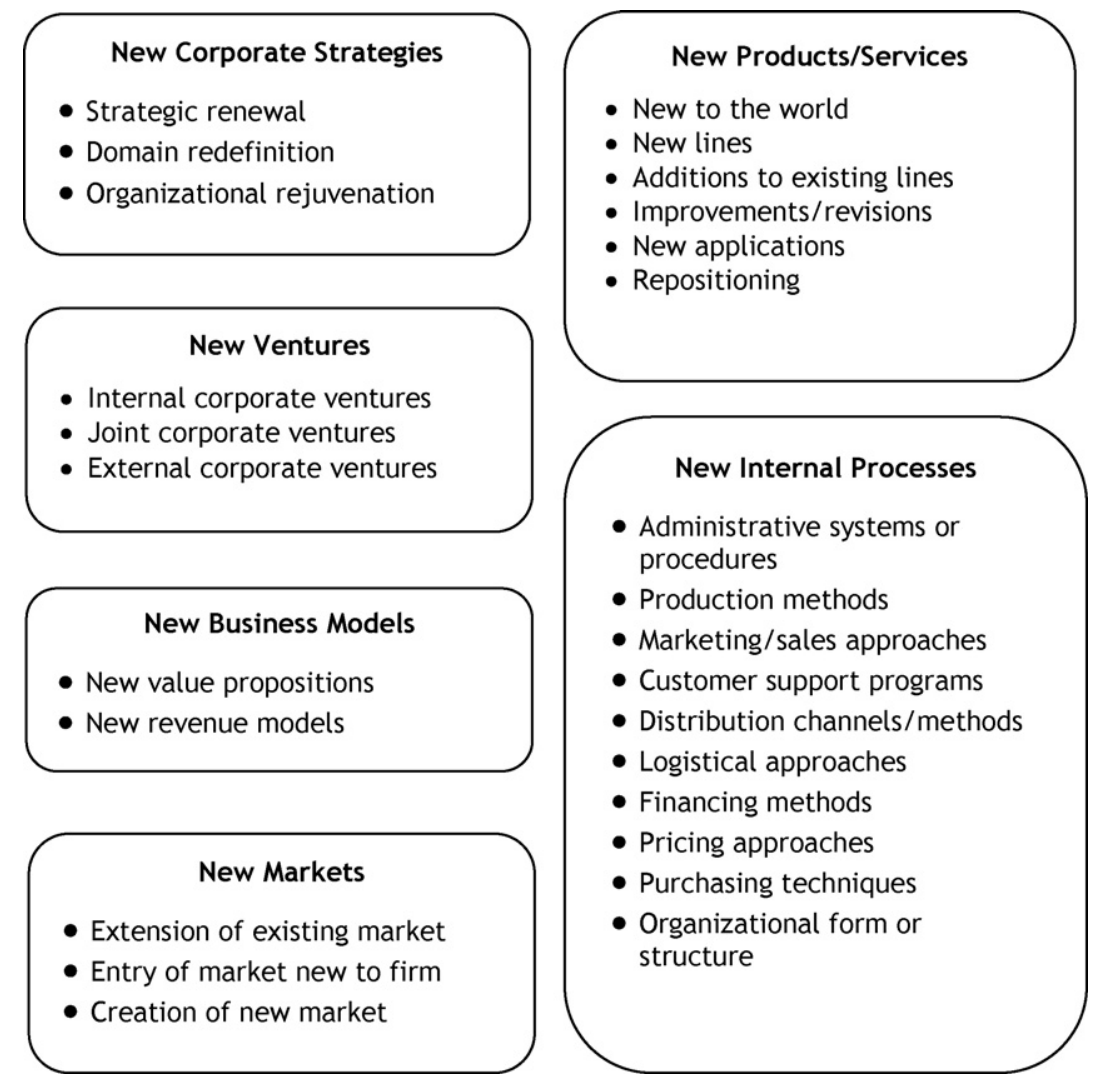




\section{Setting the stage for entrepreneurial outcomes}

Entrepreneurship is a process of recognizing or creating, and then exploiting, opportunities. As a process it is a universal phenomenon. It occurs in differing degrees and frequencies within companies, such that some firms are highly entrepreneurial and others are relatively low in terms of their entrepreneurial orientation (Dess \& Lumpkin, 2005). The overarching question for managers becomes one of determining how entrepreneurial they wish the company to be, or the role that entrepreneurship should play within the firm.

More fundamentally, fostering corporate entrepreneurship becomes problematic if company executives do not know what they are trying to achieve. While one ultimately must get employees to think and act in entrepreneurial ways, the beginning point is to specify desired CE outcomes. These outcomes can take a variety of forms, from the creation of entirely new ventures by the firm, to innovative changes in the strategy, business model, product portfolio, market boundaries, or operations of the firm. Figure 1 illustrates how the principal outcomes fall into six major categories.

Based on these potential outcomes, it becomes important to set measurable goals to guide the entrepreneurial efforts of a firm. Just as goals are established for revenue, profits, new accounts, service levels, and related variables, goals have to be set for entrepreneurship. Managers must determine targets for new ventures, new products, process improvements, markets entered, and so forth. At a more basic level, decisions must be made regarding the frequency (number of entrepreneurial initiatives) and the degree (extent to which each initiative is innovative, risky, and proactive) of entrepreneurship in these different outcome areas (Morris, 1998). Further, areas must be established in which the firm will be an innovation leader versus a follower, a priority placed on product versus service innovation, the proportion of employee time devoted to new versus existing initiatives determined, and the amount and types of innovation to come from different levels within the organization specified. These are critical decisions, as the skills, resources, and organizational structures required to produce these various types of entrepreneurial outcomes vary considerably.

Entrepreneurial activity should be the norm, not the exception, in companies. At the same time, these initiatives should not be pursued in a completely random or piecemeal fashion. An effective risk management strategy finds the firm managing a dynamic portfolio of entrepreneurial initiatives (Ireland, Kuratko, \& Morris, 2006). At any point in time, a significant number of formal projects are underway, some of which might be radical new directions or breakthrough products or services, while others might be incremental improvements to existing products and processes. The key is balance across projects. Management attempts to draw a balance between (1) high risk, high return projects against lower risk, lower return projects; (2) discontinuous or dynamically continuous innovation against continuous innovation and imitation; (3) projects with shorter development cycles and payoffs against ones with longer-term outcomes; (4) products/services intended for markets the firm currently serves against ones for markets that may not exist; and (5) projects utilizing new and emerging technologies against those relying on technologies with which the firm is familiar. A portfolio approach is also likely to result in a more balanced view of failure within the organization, as the emphasis is on returns from the overall mix of initiatives, with less reaction to the failure of a given project.

Implementation of a portfolio approach requires that senior executives approach entrepreneurship as a company-wide task, not the responsibility of the select few. The basic assumption becomes, "every employee is an entrepreneur." As such, the portfolio concept is extended to include hundreds of informal and early incubation initiatives within the company. Therefore, in addition to major projects with significant investments unfolding over a number of years, a wide array of simple process innovations are in gestation as employees look for innovative ways to accomplish job tasks in ways that save time, reduce costs, improve performance, or create more value. Take the example of the airline whose flight attendant suggests loading a plane with only enough ice for passengers' drinks for a one-way flight to one destination, where conventionally enough ice was loaded for the return flight. The stewardess saves the company a significant amount of money and, while her idea was certainly not a breakthrough innovation, it helps improve the company's competitive position. Between these two extremes is a complement of intermediate range initiatives, from product line extensions and product improvements to adoption of new-to-the firm processes and new market entries.

Critical to this kind of employee empowerment is the need for managers to convey a clear concept of entrepreneurship to personnel at each level and in each functional area of the firm. Employees cannot simply be exhorted to "be more entrepreneurial." A common problem in companies, and one that many 
executives fail to appreciate, is that employees do not know what is being asked of them when told to show initiative, take calculated risks, and innovate on the job. The implication is that corporate entrepreneurship is an exercise in managing expectations. Parameters must be outlined regarding forms and types of entrepreneurial outcomes that correspond to a given type of job. Identifying role models and disseminating case studies that reflect the kinds of entrepreneurial behavior sought by management can also be helpful in establishing expectations.

\section{Creating the climate: Facilitators of corporate entrepreneurship}

Consistently achieving the entrepreneurial outcomes presented in Figure 1 requires that managers address perhaps the most vexing challenge of all: institutionalizing entrepreneurship within the mainstream of the company. Unfortunately, the inherent tendency as companies evolve is to move away from entrepreneurship. Without intending to do so, companies naturally drift in the direction of control, structure, and bureaucracy. Entrepreneurship represents a countervailing and disruptive force that must be cultivated. Consistent with the notion of a step up to the plate philosophy, the challenge is to create work climates that allow employees to recognize and act upon their entrepreneurial potential. A simple framework for capturing the various mechanisms, or design elements, available for doing so can be found in Figure 2. This framework includes four key building blocks instrumental for designing work environments that support the firm's entrepreneurial strategy. These include:

1. Culture: the organization's basic beliefs and assumptions regarding what the company is about, how its members should behave, and how it defines itself relative to its external environment.

2. Structure: the formal pattern of how people and jobs are grouped, and how the activities of different people or functions are connected.

3. Resource Controls: the formal and informal mechanisms that help managers ensure that resources are obtained and used efficiently and effectively.

4. Human Resource Management: the set of tasks associated with acquiring, training, developing, motivating, organizing, and maintaining the employees of a company.
Figure 2. Variables that combine to create entrepreneurial work environments

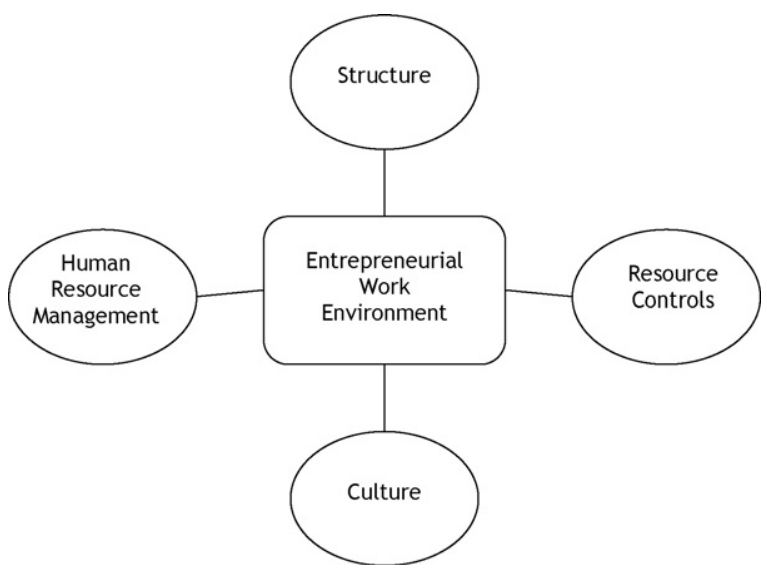

While each of these elements lends itself to specific managerial actions, they are highly interdependent. Therefore, the values, norms, and symbols that make up company culture are intertwined with the approach to control over resources, which interacts with the company structure. Similarly, human resource management practices in areas such as job design, employee recruitment, and reward systems affect and are affected by structure, controls, and culture.

In attempting to address these four elements, where should managers focus? Various researchers have identified ways in which these elements can be designed to encourage entrepreneurial behavior (e.g., Green, Covin, \& Slevin, 2008; Hamel \& Breen, 2007; Kuratko, Ireland, Covin, \& Hornsby, 2005; Rutherford \& Holt, 2007). General findings from this work suggest that entrepreneurship is more likely in corporate cultures that reinforce innovation and change, an ongoing sense of urgency, employee empowerment, hands-on management, freedom to grow, and room to fail. Structures that are flatter, with broader spans of control, open communication, and participative decision-making, are also associated with higher levels of entrepreneurship. The same is true for control systems that are flexible, emphasize resource slack, and allow discretion over how resources are used. With regard to human resource management practices, jobs are designed to be broader in scope, with career paths that are flexible, appraisals that include explicit criteria to assess innovative and risk-taking behaviors, and reward systems that provide incentives that reinforce and reflect the nature of entrepreneurial initiatives.

As we shall see, underlying this design process is a set of seemingly contradictory dimensions that should become the primary focus of the company's 
efforts. In fact, it is within these contradictions that the essence of entrepreneurship can be found.

\section{The architecture of balance}

As summarized in Figure 3 , the aforementioned underlying dimensions include the relative emphasis on (1) exploration vs. exploitation; (2) individualism vs. collectivism; (3) structural autonomy vs. restraint; (4) resource tightness vs. looseness; (5) performance incentives vs. professional security; and (6) administrative vs. entrepreneurial skills. While each of these is rooted in a particular design element, as we shall see, each affects all of the elements. At issue, then, is how managers approach what appears to be a set of dichotomies.

A climate that fosters entrepreneurship is built around the principle of balance. Balance does not imply compromise. Rather, it is the ability to simultaneously capitalize on the advantages of two contrasting, if not opposing, forces. Elements of both forces are allowed to co-exist, creating a degree of healthy abrasion within the firm. Neither of the two forces is allowed to overwhelm the other, although the company goes through periods where one force may be more prominent. Birkinshaw (2003) alludes to this kind of balance in referring to the "paradox of corporate entrepreneurship."

The real middle ground lies not in lessening two extremes by striving for the average, but instead in allowing for co-existence. Sustainable entrepreneurship results not from compromise, integration, or bipolar tensions, but the simultaneous existence of two inconsistent states. Eisenhardt (2000, p. 703) refers to this phenomenon as a "duality of coexisting tensions." The manager rejects a focus on simple interactions as a series of opposites and differences, and accepts that the forces are also interdependent and can complement one another in a movement between order and disorder, acting in the process as a source of creative potential.

Take, as an example, the question of whether entrepreneurship flourishes in companies which place primacy on individualism versus those which stress the team or the collective; this is an issue we shall explore in more depth later. The answer is that strong emphasis must be placed on both. Individuals are prized, for they are the ones who originate ideas, champion innovations against the inherent forces of resistance, build teams and keep them together, and persevere in the face of rejection and failure. Yet, there is no successful entrepreneurship without teams. The implication is that both individuals and teamwork must be supported and rewarded, and this is accomplished in different ways. Daring individuals play certain roles, while collaborative teams play others.

An organization's prowess in achieving balanced co-existence is a type of "dynamic capability" whereby two very different strategic logics must simultaneously be managed (Eisenhardt \& Martin, 2000). Organizations vary in terms of their capabilities in this regard, and it is much easier to allow a single logic to dominate. A common reaction to this dilemma is to try and build structural forms where disparate logics can be separated from one another, such as with the creation of relatively autonomous new venture divisions. At the same time, a prolonged period of strong imbalance will prove dysfunctional to the organization. It can result, on the one hand, in an overly insular company with a burgeoning bureaucracy or, on the other hand, in a preponderance of misdirected and overly risky initiatives upon which the organization fails to meaningfully capitalize.

Let us now further explore how the concept of balance applies to each of the variables in Figure 3.

Figure 3. Achieving corporate entrepreneurship through co-existing properties

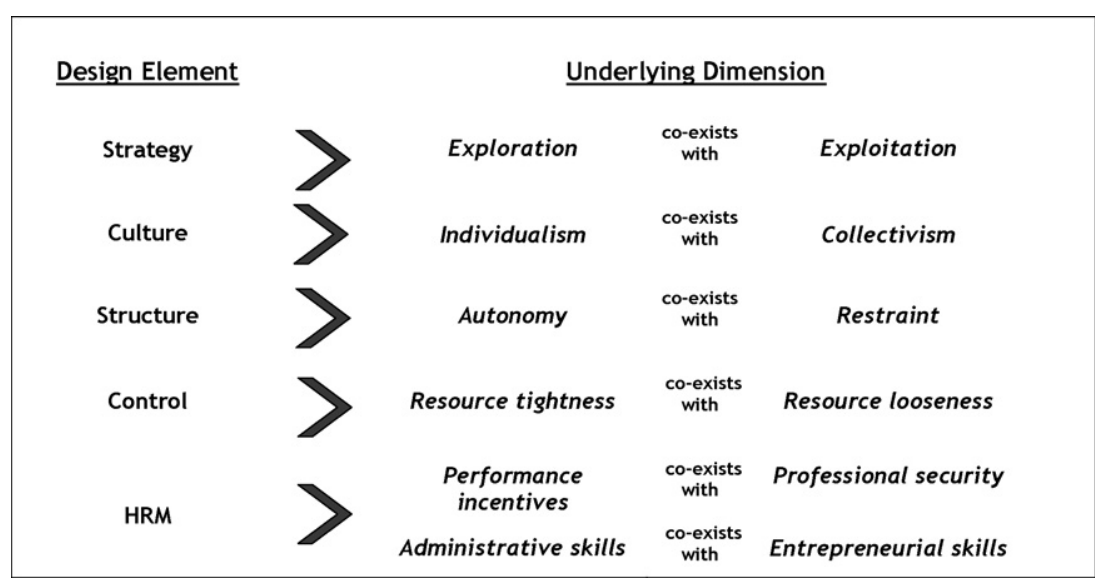




\subsection{Strategy: Balancing exploration and exploitation}

As firms strive to be more entrepreneurial, a fundamental question concerns the relative emphasis on exploration versus exploitation. In this context, exploration finds resources devoted to search, discovery, experimentation, and innovation, while exploitation involves an emphasis on refinement, adaptation, selection, implementation, and efficiency (He \& Wong, 2004; March, 1991; Schildt, Maula, \& Keil, 2005). There are companies quite adept at exploration, such as Xerox-which, however, struggles with the exploitation of many of its breakthroughs (Cooper, 2003). Similarly, Church \& Dwight Co., Inc.--makers of Arm and Hammer Baking Soda-is a master of exploitation, with relatively little exploratory emphasis. The firm has applied innovative thinking to stimulate product usage rates by identifying dozens of alternative product applications, while capitalizing on a brand with incremental line extensions. Organizations that are good at doing both simultaneously are referred to as "ambidextrous" (Tushman \& O'Reilly, 2002). The ability to generate the kinds of returns necessary to substantiate ongoing exploratory activity is directly tied to exploitation capabilities. The inherent nature of exploration is a relatively high ratio of failures or projects abandoned along the way to projects that get to a commercialization or implementation stage. The returns from exploitation have to cover all of these initiatives. Absent exploitation capabilities, skepticism develops regarding "pie in the sky" innovation. Yet, as one invests further in exploitation, a natural resistance begins to build to major exploratory effort. Flexible skills and procedures are gradually converted into rigid, uniform routines (DeLanda, 2000). Those involved with exploitation become more concerned with incremental changes to existing products, line extensions, and expansion of existing markets.

While it is generally assumed that entrepreneurship is associated with exploration, the reality is that exploitation is also intimately tied to entrepreneurial capabilities. However, the entrepreneurship of exploration is not the same as the entrepreneurship of exploitation. In exploration, entrepreneurship is about discovery, recognition, or the creation of opportunity, the translation of opportunity into highly innovative business concepts, risk assessment, and creative destruction in the marketplace. In exploitation, entrepreneurship is concerned with creative approaches to mitigating and managing risk, leveraging resources, bootstrapping, guerrilla skills associated with implementation of new concepts and approaches, and novel methods for overcoming obstacles (Tidd \& Taurins, 1999).

Consistent with this discussion is the proposition that there is no such thing as too much entrepreneurship within a company. This is counter to the position taken by some researchers that companies need to be "just entrepreneurial enough" (Bhuian, Menguc, \& Bell, 2005), or that they must avoid entrepreneurial excess (Birkinshaw, 2003). Perhaps this issue is not one of trying to limit the amount of entrepreneurship in companies, as there is always room for more imagination, improvement, creativity, and initiative in any facet of company operations. Instead, the issue is one of ensuring there is strategic direction to entrepreneurial behaviors - such as with the balanced portfolio discussed earlier-and that exploration is balanced with exploitation, and ethical boundaries are imposed around how entrepreneurial initiatives are pursued. While conventional wisdom suggests that Enron was simply too entrepreneurial, the reality may have had less to do with entrepreneurship per se, and more to do with a lack of ethical boundaries coupled with extremely high performance expectations.

\subsection{Culture: Balancing individualism and collectivism}

Entrepreneurship does not happen without individuals. Someone must champion a concept, persevere in the face of resistance and rejection, make adaptations, and keep the idea alive (Greene, Brush, \& Hart, 1999). A central feature of any entrepreneurial endeavor is passion, something that clearly is the province of individuals. But entrepreneurship also does not happen without teams (Francis \& Sandberg, 2002).

A motivated, coordinated group of individualseach having their own skills to offer and contributions to make-is critical for moving an entrepreneurial event through what can be a lengthy process filled with obstacles. This brings us to a value debate that exists in most companies: individualism versus collectivism.

Individualism refers to a self-orientation, an emphasis on self-sufficiency and control, the pursuit of individual goals that may or may not be consistent with those of one's colleagues, and a value system whereby people derive pride from their own accomplishments. A collective orientation involves subordination of personal interests to the goals of the larger work group, an emphasis on sharing, a concern with group welfare, and antipathy toward those outside the group.

In a work context, there are positive and negative aspects to both individualist and collective 
orientations (Morris, Allen, \& Avila, 1993). An individualistic ethic may foster development of individual self-confidence, lead to a greater sense of personal responsibility, create more of a competitive spirit, and produce breakthrough ideas. At its extremes, it can also produce selfishness, higher levels of stress, interpersonal conflict, and unethical behavior. A group orientation offers the advantages of more harmonious relationships among individuals, greater synergies, more social support, and can result in a steady stream of incremental improvements and moderate innovations. On the downside, a group focus can entail the loss of individual identity, greater emotional dependency, a tendency to "free ride" on the efforts of others, compromises instead of optimizing behavior, and "group think" whereby individuals get locked into a singular shared way of viewing or approaching a problem.

A strong spirit of individualism would seem consistent with the modern corporation, with its lateral structures, where career paths are no longer well defined and employees must create their own futures within the organization. Unfortunately, reality tends to be quite different. Organizations are, by definition, collective entities. They are concerned with serving the collective interests of their members. The individualistic nature of entrepreneurship is a primary reason that entrepreneurial behavior is resisted within organizations. It can appear, certainly in the shorter term, to conflict with or threaten collective interests. Where there are individuals acting as agents of change and attempting to pursue agendas that entail risk, the collective has an incentive to oppose or constrain them.

The ability to achieve sustainable entrepreneurship in a company is dependent upon a balance between the need for individual initiative and the spirit of cooperation and group ownership of innovation. Empirical evidence exists that such a balance can be found in highly entrepreneurial companies (Morris, Allen, \& Avila, 1993). As the entrepreneurial process unfolds, the individual champion requires not just specialist expertise but teams of people, some of whom can fill multiple roles. Members of these teams are able to collaborate in meeting tight timelines, identifying and overcoming unanticipated obstacles, and finding approaches and opportunities that often redefine the original concept, putting it on a more successful path. Sometimes it is the entrepreneur who keeps the team on track, and other times it is the team that is the voice of reason and consistency. All the while, disruptive projects must be able to co-exist with everyday operations; most of the infrastructure within the firm is designed to support everyday operations. The culture has to balance the individualism tied to passion for new opportunities with a commitment to the greater collective objectives of the corporation.

\subsection{Structure: Balancing autonomy and restraint}

Process and product innovation involve the unknown, and imply change. The ability to bridge the unknown and overcome resistance to change is consistent with higher levels of autonomy, whereby employees are empowered to exercise discretion and personal initiative in their jobs (Marginson, 2002). Autonomy is reflected in structures that are more lateral than vertical, with broader spans of control and where jobs are more flexibly defined. It is the need for autonomy that tends to drive a manager's entrepreneurial behavior. But unrestrained autonomy can result in employees exploring new and different possibilities that translate into unrealistic concepts, projects that are inconsistent with the strategic direction of the firm, and initiatives with resource requirements that exceed potential returns.

Personal freedom manifests itself in many ways within a company, and its suppression is typically pursued for any number of specific purposes. Again, however, rather than think in terms of trade-offs, high levels of autonomy can co-exist with significant restraints on group or individual behaviors. At issue is how much the firm wants to suppress the freedom to invent, improve, modify, or enhance. The implication is that companies must strike a balance whereby discretion co-exists with direction and controls, and autonomy can be earned. Further, higher amounts of autonomy must be coupled with clear vision, well-communicated direction, and well-stated goals.

Autonomy can be applied at different levels within the structure, including the division or unit, department or functional area, team, and individual. It implies an ability to employ-at a given level of the organization-different procedures, processes, decision rules, budgeting methods, management styles, communication channels, reward systems, and performance measures. Further, it should vary based on the type of entrepreneurship sought by the company. Incremental innovation can occur in more restrained environments, while discontinuous innovation requires considerable autonomy. Therefore, process improvements within the mainstream functional areas of a company require relatively low levels of autonomy at the department or individual level, while a fairly autonomous new venture division is likely to demonstrate a high level of 
autonomy. More generally, in an environment that recognizes the value of autonomy, there is more likely to be an informal or underground economy that is used to circumvent the official structures in order to achieve results.

\subsection{Control: Balancing resource tightness and looseness}

A quarter century ago, Peters and Waterman (1982) posited that the best-run companies had simultaneous "loose-tight" properties whereby the organization is "rigidly controlled, while at the same time autonomy, entrepreneurship and innovation from the rank and file is encouraged" (p. 318). Tightness of resources serves to ensure accountability while encouraging bootstrapping, and can force people to challenge existing ways of doing things. Looseness of resources provides room for experimentation and adaptation, especially with new concepts that have yet to win management approval. More recently, Collins (2001) has suggested that what he terms "great" companies have a culture of discipline, where rigor and discipline enable creativity and entrepreneurship. This creative duality is expressed in terms of "freedom within a framework" and "opportunistic flexibility," where policies and procedures serve as boundaries to guide and optimize entrepreneurial efforts.

When it comes to the allocation of resources, entrepreneurship would seem to require fiscal discipline, but with budget mechanisms that are flexible in accommodating new opportunities as they emerge, and organizational goals that are focused on achieving ends rather than prescribing means. The likelihood of entrepreneurial behavior would seem greater when enlightened efficiency is emphasized. Thus, the organization has clear and specific financial accountability. Otherwise, significant money is wasted on ill-conceived or inappropriate initiatives. However, rather than strictly imposing detailed line-item budgets on all facets of operations, broader expenditure categories are emphasized, a level of slack is deliberately designed into cost controls and budgeting, budgetary deviations within broader categories are more tolerated, performance measurement does not have to occur at fixed intervals, and success measures include financial and non-financial indicators. The budgetary system may include incentives tied to organizational success factors and goal congruence.

Morris, Schindehutte, and Allen (2006) provide empirical evidence that this balanced approach to resource tightness-looseness produces the highest levels of entrepreneurship in organizations. They conclude that fiscal controls must strongly emphasize outcomes and individual accountability, while also including resource slack that permits individuals and teams to experiment with initiatives that are consistent with the firm's objectives.

\subsection{Human resources: Balancing incentives and security}

In his classic article entitled "On the folly of rewarding A while hoping for B," Kerr (1995) argues that people look for cues concerning which activities are rewarded and then act accordingly, often to the exclusion of activities not rewarded. The reward system stipulates the contributions expected from employees and expresses values and norms to which those in the firm must conform. When properly designed, rewards are a compelling instrument that can mobilize organizational commitment and build an entrepreneurial culture, which can lead to successful strategy execution.

Most compensation and reward systems are not designed to promote corporate entrepreneurship, and many actually suppress innovative behaviors. To be effective, rewards should reflect three considerations. First, they must create an "up-side" for managers willing to take calculated risks. Examples include milestone awards, which can entail four to five times the salary of an employee over a period of years, bonuses tied to project risk levels, and teams sharing a percentage of profits from their entrepreneurial initiatives (Block \& MacMillan, 1995). Second, financial incentives are sometimes less important than social incentives, including formal acknowledgement from management, granting of freedom, and the allocation of company resources to support employee ideas.

Third, the predictability of a paycheck and the associated benefits is partly what attracts many to choose a corporate career rather than an entrepreneurial career. To provide security against the downside of entrepreneurial risk taking, an adequate salary and benefits package should be at the core of compensation. Morris and Jones (1993) provide clear evidence of the importance of security in highly entrepreneurial companies. A balance between incentives-financial and nonfinancial-and the security needed by employees can contribute to a work environment of controlled freedom, where executives get out of the way of those they empower to execute strategy.

There are two reasons for creating a balance between incentives and security for corporate entrepreneurs. First, in many corporations there exists a genuine and historically justified fear of failure. Employees have observed over time that risk taking has resulted in very little 
real up-side (rewards or recognition) and unlimited down-side (failures have resulted in termination). Second, the need for a degree of security in compensation is magnified by the reality that the outcomes of entrepreneurial activity are often long-term. Any benefits to the corporation from their entrepreneurial actions may not be completely realized until long after the managers involved have moved on to new positions and different areas of responsibility.

When incentivizing entrepreneurship, the criteria for evaluating performance should be tied to both direct and indirect benefits to the organization. Direct benefits of innovation include financial outcomes such as revenue and profit streams from new lines of business, and improved productivity from process innovations. Indirect benefits, although more difficult to assess, are also important to recognize and reward. For example, even though some initiatives may fail, they may be judged as ultimately worthwhile if what is learned from the failure helps future initiatives succeed, or if the team clearly learned skills that will improve their performance in future innovations. Rewarding seemingly failed efforts is antithetic to most corporate reward systems, but if the risks taken were prudently planned and properly executed, a failed initiative must be rewarded as if it were a success. Rewarding the process of innovation and the prudent risk taking that is part of the process of entrepreneurship can be even more important than simply rewarding employees based on the outcomes of any innovation.

\subsection{Human resources: Balancing administrative and entrepreneurial skills}

The experience of entrepreneurship-especially when in the midst of pursuing a novel concept-is one of ambiguity, stress, loneliness, exhilaration, and uncertainty. It is filled with peaks and valleys. Both predictable and unpredictable obstacles arise, and ongoing adaptation is required as continuous learning takes place. For managers and employees to act on their innate entrepreneurial potential requires development of a set of entrepreneurial competencies. These include opportunity recognition, opportunity evaluation, risk mitigation and management, resource leveraging, guerrilla skills, creative problem solving, and planning when nothing exists. These competencies must co-exist with the more conventional administrative competencies of managers, including organizing, coordinating, staffing, directing, budgeting, controlling, and motivating, as well as political skills.
This conclusion is consistent with the work of Stevenson (1999), which distinguished two general types of managerial approaches within firms: the trustee and the promoter. The trustee fosters efficient management by emphasizing the effective utilization of resources. This type of manager is slow to act, but makes durable commitments when action is taken. He or she aims to reduce personal risk by working with resources currently controlled by the organization. He or she has a need for clearly identified roles, responsibilities, and authority. Alternatively, the promoter is opportunity-driven, and pursues opportunities regardless of resources currently under control. He or she is action-oriented and manages risks through staged commitment of resources, while being adept at leveraging the resources of others. He or she operates well through flexible structures and informal networks. The promoter is, in essence, the corporate entrepreneur.

As with our other dimensions, both types of management have to be supported. Entrepreneurial skills are the key to creating the future, while administrative skills are the key to exploiting that future as it is created. The ultimate success of a given manager may be tied to his or her ability to adroitly fill both roles. Although the administrative role tends to dominate in organizations, ongoing periods of rapid and threatening change in the external environments of companies highlight the vital role of the manager as entrepreneur.

\section{Challenges of implementation}

The implementation of change in companies tends to follow a pattern that is relatively continuous (Weick \& Quinn, 1999). The organization makes a series of incremental adaptations to changes in the external environment, including both the macro environment of the firm and its competitive environment. Once the decision is made to make an adaptation, measurable objectives anticipated from change are identified so that annual evaluation of the effectiveness of the change can be determined. Functional strategies necessary for implementation are then developed. Finally, concise policies to guide decision-making and management actions within the context of the change are put in place. The pace of continuous change tends to be both dogged and deliberate. Changes are often at the margins and are limited to the functional level of the company, rather than involving a focus on organization transformation. Implementation focuses on creating consensus throughout the organization, followed by necessary adaptations within the affected functional units and departments. 
At the other extreme, implementation can take a course that attempts to overcome inertia through revolutionary change (Ford \& Ford, 1994). At its core, corporate entrepreneurship is often a revolutionary form of implementing change; it can lead to the creation of new business lines which exploit market opportunities, or adapt to fundamental changes that might threaten survival of the business as extantly positioned. Revolutionary change also takes place through the implementation of radical changes in the culture, structure, controls, and human resource systems of the organization to align with the changes in strategy.

Continuous and revolutionary approaches to the implementation of change might seem to be diametrically opposed. In reality, highly entrepreneurial organizations have both types of change occurring in parallel (Meyer \& Stensaker, 2007). Continuous, incremental change occurs at the functional and operational levels at the same time that revolutionary, radical changes are happening at the business level. It should also be noted that the very nature of how radical change actually takes place in many corporations naturally balances continuous and revolutionary change. Much of what is considered revolutionary change, when viewed in hindsight, has actually emerged continuously (Plowman et al., 2007).

The parallel emphasis on incremental and revolutionary change requires a work environment that can simultaneously accommodate order and disorder, fluctuation and stability, non-linearity and linearity, randomness and non-randomness, and both discrete and emergent phenomena. This is a notoriously difficult challenge, and is a reason that firms often falter at the implementation stage of corporate entrepreneurship. They tend to look for one "holy grail" in terms of the ideal way to structure entrepreneurial initiatives. Thus, they will launch a corporate new ventures division, create an opportunity review board, appoint a vice-president of entrepreneurship, or launch an internal venture capital fund-and then assume that entrepreneurship will be automatically in press.

There is no one specific or correct way in which to implement corporate entrepreneurship. The need is for a multi-faceted and comprehensive approach that reflects the kinds of innovation the firm seeks at different levels of the organization. It requires a sustained commitment to an entrepreneurial future on the part of senior management. This commitment must be coupled with ongoing attempts to properly craft the work environment around a harmonious blend of the elements of strategy, structure, culture, resource control, rewards, and skills so as to produce an ethic of entrepreneurship throughout the firm. The crafting of a work environment is always a work in progress.

These design elements are highly interdependent, and proper implementation requires that managers recognize the role each of them plays in balancing exploration and exploitation, individualism and collectivism, autonomy and restraint, tightness and looseness of resources, incentives and security, and administrative and entrepreneurial capabilities. While the paradoxical forces tend to be primarily rooted in one of the design elements (e.g., individualism/collectivism is rooted in the culture of the company), they are manifested through all five of the design elements in tandem. Therefore, the parallel forces of individualism and collectivism can be encouraged based on the interplay among (1) the types of goals and nature of the innovation portfolio sought through the strategy for entrepreneurship; (2) the amount of autonomy made possible through the company structure and job design; (3) the budgetary flexibility built into the control system; and (4) the criteria around which performance appraisals are conducted and rewards are given as part of the firm's human resource management efforts.

Proper implementation must also reflect the ways in which these paradoxical forces affect one another. Successful exploration is more likely when employees have more autonomy and confront looser controls, individual initiative is prized, and entrepreneurial skills are well developed. The ability to engage in successful exploitation is especially tied to administrative skills, tighter controls, and collective action. Yet the duality remains, in that exploration and exploitation are enabled by the forces on both sides of each paradox.

The company reward system provides a clear illustration of these various interactions. Extrinsic and intrinsic rewards can be used to encourage different types or degrees of innovativeness, balancing exploration and exploitation. They can support individual initiative while at the same time reinforcing team collaboration. They can include equity-based incentives such as profit sharing, phantom stock, stock appreciation rights, and stock options to create longer-term incentives for entrepreneurship tied to company performance. Meanwhile, raises and bonuses can reinforce particular entrepreneurial actions in the short-run. In more autonomous structures, rewards can be customized and presented as choices, allowing employees to select the rewards that appeal to them, thus also balancing incentives and security. Publicly acknowledging and praising entrepreneurial champions for their efforts helps to bolster the perceived intrinsic reward that employees get from the act 
of innovation. The importance of entrepreneurship then becomes a part of the culture, which will be continuously reinforced as a core value shared by all members of the organization.

\section{Order and chaos}

As firms confront increasingly turbulent competitive environments, entrepreneurship becomes the key to sustainable competitive advantage. To capitalize on its potential, managers must appreciate that entrepreneurship is an inherently ambiguous, unpredictable, and emergent phenomenon. Opportunities are not discrete things that pre-exist, or are simply capitalized upon; they are emergent and in the making, such that the actions of the entrepreneur open doors that create new parameters and aspects of a given opportunity. Entrepreneurial projects evolve in non-linear and somewhat chaotic ways. This being the case, it is virtually impossible to control entrepreneurship within companies. It can, however, be nurtured, directed, and channeled. As Bygrave (1989, p. 28) has noted, "entrepreneurship, after all, is a science of turbulence and change, not continuity." Novelty creating processes and order creating processes must co-exist. Terms like "controlled chaos" and "managing the unknown" capture the task of those who champion entrepreneurial concepts.

For their part, organizations are collectives that tend to move naturally over time toward an emphasis on exploitation, structure and restraint, tight control, and security, where a priority is placed on administrative skills (Garvin \& Levesque, 2006). In contrast, the forces of exploration, autonomy, loose control, individualism, meaningful individual incentives, and promoter skills run counter to these natural organizational tendencies. While critical for survival, these countervailing forces appear threatening and disruptive to those within the corporate mainstream. It is the enlightened leader who understands the need to remain vigilant in maintaining work environments where both sets of forces can coexist, and dynamic tensions within the company are cultivated. He or she further understands that these two sets of forces can reinforce and enhance the contributions of one other. Thus, Coleman (1999) notes that "for employees to have enough confidence to take risks and experiment, there must be some stability in the organization; similarly, some order is necessary for employees to recognize novelty" (p. 37).

As the pendulum swings back and forth between these co-existing elements, organizations move from being highly entrepreneurial to becoming large bureaucracies, and sometimes bureaucratic firms can become entrepreneurial. When the pendulum is allowed to swing too far in one direction, the result can be the inertia one finds in the United States automobile industry today, on the one hand, or the uncontrolled direction that characterized the demise of Enron.

Contemporary organizations are in the midst of a dramatic and ongoing transformation as they downsize, right-size, restructure, re-engineer, outsource, and form strategic alliances to ensure their futures. The future will find the survivors to be less hierarchical and more circular, less tied to fixed assets and more virtual, and generally faster, better able to customize, more flexible, and more global. Yet changes such as these require direction as managers seek to make sense of an increasingly dynamic, hostile, and complex landscape. Entrepreneurship is the compass that can guide these efforts, as it is sustainable only when balance is maintained between these seemingly contradictory forces.

\section{References}

Bhuian, S., Menguc, B., \& Bell, S. (2005). Just entrepreneurial enough: The moderating effect of entrepreneurship on the relationship between market orientation and performance. Journal of Business Research, 58(1), 9-17.

Birkinshaw, J. (2003). The paradox of corporate entrepreneurship. Strategy \& Business, 21(3), 46-58.

Block, Z., \& MacMillan, I. (1995). Corporate venturing: Creating new business within the firm. Boston: Harvard Business School Press.

Bygrave, W. D. (1989). The entrepreneurship paradigm: A philosophical look at its research methodologies. Entrepreneurship Theory and Practice, 14(1), 7-30.

Coleman, H. J. (1999). What enables self-organizing behavior in businesses? Emergence, 1(1), 33-48.

Collins, J. (2001). Good to great. New York: HarperCollins.

Cooper, R. (2003). Profitable product innovation: Critical success factors. In L. Shavinina (Ed.), The international handbook on innovation (pp. 139-157). New York: Elsevier.

DeLanda, M. (2000). A thousand years of non-linear history. New York: Zone Books.

Dess, G., \& Lumpkin, T. (2005). The role of entrepreneurial orientation in stimulating effective corporate entrepreneurship. Academy of Management Executive, 19(1), 147-160.

Eisenhardt, K. (2000). Paradox, spirals, ambivalence: The new language of change and pluralism. Academy of Management Review, 25(4), 703-705.

Eisenhardt, K., \& Martin, J. (2000). Dynamic capabilities: What are they? Strategic Management Journal, 21(12), $1105-1121$.

Ford, J. D., \& Ford, L. W. (1994). Logics of identity, contradiction, and attraction in change. Academy of Management Review, 19(4), 756-785.

Francis, D. H., \& Sandberg, W. R. (2002). Friendship within entrepreneurial teams and its association with team and venture performance. Entrepreneurship Theory and Practice, 25(2), 5-25. 
Garvin, D. A., \& Levesque, L. C. (2006). Meeting the challenge of corporate entrepreneurship. Harvard Business Review, 84(10), 102-112.

Green, K., Covin, J., \& Slevin, D. (2008). Exploring the relationship between strategic reactiveness and entrepreneurial orientation: The role of structure-style fit. Journal of Business Venturing, 23(3), 356-375.

Greene, P. G., Brush, C. G., \& Hart, M. H. (1999). The corporate venture champion: A resource-based approach to role and process. Entrepreneurship Theory and Practice, 22(2), 103-122.

Hamel, G., \& Breen, B. (2007). The future of management. Boston: Harvard Business School Press.

He, Z., \& Wong, P. (2004). Exploration vs. exploitation: An empirical test of the ambidexterity hypothesis. Organization Science, 15(4), 481-494.

Ireland, R. D., Kuratko, D. F., \& Morris, M. H. (2006). The entrepreneurial health audit: Preparing firms for corporate entrepreneurship. Journal of Business Strategy, 27(1), 10-17.

Kerr, S. (1995). An academy classic: On the following of rewarding A while hoping for B. Academy of Management Executive, 9(2), 99-108.

Kuratko, D. F., Ireland, R. D., Covin, J., \& Hornsby, J. (2005). A model of middle-level managers' entrepreneurial behavior. Entrepreneurship Theory and Practice, 29(6), 699-716.

March, J. G. (1991). Exploration and exploitation in organizational learning. Organization Science, 2(1), 71-88.

Marginson, D. E. (2002). Management control systems and their effects on strategy formulation at middle management levels: Evidence for a U.K. organization. Strategic Management Journal, 23(11), 1019-1031.

Meyer, C., \& Stensaker, G. (2007). Managing multiple change processes: Challenges and intervention techniques. In Proceedings of the Annual Academy of Management Conference (pp. 1-6). Philadelphia: Academy of Management.

Morris, M. H. (1998). Entrepreneurial intensity. Westport, CT: Quorum Books.
Morris, M. H., Allen, J., \& Avila, A. (1993). Individualism and the modern corporation: Implications for innovation and entrepreneurship. Journal of Management, 19(3), 595-613.

Morris, M. H., \& Jones, F. (1993). Human resource management practices and corporate entrepreneurship: An empirical assessment. International Journal of Human Resources Management, 4(4), 873-896.

Morris, M. H., Kuratko, D. F., \& Covin, J. (2008). Corporate entrepreneurship and innovation. Mason, $\mathrm{OH}$ : Thomson Southwestern.

Morris, M. H., Schindehutte, M., \& Allen, J. (2006). Balanced control systems as a mechanism for achieving corporate entrepreneurship. Journal of Managerial Issues, 18(4), 468-495.

Peters, T., \& Waterman, R. (1982). In search of excellence: Lessons from America's best-run companies. New York: Warner Books.

Plowman, D., Baker, L., Beck, T., Mukta, K., Solansky, S., \& Travis, D. (2007). Radical change accidentally: The emergence and amplification of small change. Academy of Management Journal, 50(3), 515-543.

Rutherford, M., \& Holt, D. (2007). Corporate entrepreneurship: An empirical look at the innovativeness dimension and its antecedents. Journal of Organizational Change Management, 20(3), 429-444.

Schildt, H. A., Maula, M. V. J., \& Keil, T. (2005). Explorative and exploitative learning from external corporate ventures. Entrepreneurship Theory and Practice, 29(4), 493-515.

Stevenson, H. H. (1999). A perspective on entrepreneurship. In H. Stevenson, M. Roberts, A. Bhide, \& W. Sahlman (Eds.), The entrepreneurial venture (pp. 1-22). Boston: Harvard Business School Press.

Tidd, J., \& Taurins, S. (1999). Learn or leverage? Strategic diversification and organizational learning through corporate ventures. Creativity and Innovation Management, 8(2), 122-129.

Tushman, M., \& O'Reilly, C. (2002). Winning through innovation. Boston: Harvard Business School Press.

Weick, K., \& Quinn, R. (1999). Organizational change and development. American Review of Psychology, 50(1), 361-386. 